\title{
A search for evidence of somatic mutations in the NF1 gene
}

\author{
Alison M John, Martino Ruggieri, Ros Ferner, Meena Upadhyaya
}

\begin{abstract}
Neurofibromatosis type I (NF1) is an autosomal dominant disorder affecting 1 in 3000 people. The NF1 gene is located on chromosome 17q11.2, spans $350 \mathrm{~kb}$ of genomic DNA, and contains 60 exons. A major phenotypic feature of the disease is the widespread occurrence of benign dermal and plexiform neurofibromas. Genetic and biochemical data support the hypothesis that NF1 acts as a tumour suppressor gene. Molecular analysis of a number of NF1 specific tumours has shown the inactivation of both NF1 alleles during tumourigenesis, in accordance with Knudson's "two hit" hypothesis. We have studied 82 tumours from $45 \mathrm{NF} 1$ patients. Two separate strategies were used in this study to search for the somatic changes involved in the formation of NF1 tumours. First, evidence of loss of heterozygosity $(\mathrm{LOH})$ of the NF1 gene region was investigated, and, second, a screen for the presence of sequence alterations was conducted on a large panel of DNA derived from matched blood/tumour pairs. In this study, the largest of its kind to date, we found that $12 \%$ of the tumours (10/82) exhibited LOH; previous studies have detected LOH in $3-36 \%$ of the neurofibromas examined. In addition, an SSCP/HA mutation screen identified five novel NF1 germline and two somatic mutations. In a plexiform neurofibroma from an NF1 patient, mutations in both NF1 alleles have been characterised.
\end{abstract} (F Med Genet 2000;37:44-49)

Institute of Medical Genetics, University College of Medicine of Wales, Heath Park, Cardiff CF4 4XN, UK A M John

M Upadhyaya

Department of Paediatric Neurology, Paediatric Clinic, University of Catania, Italy

M Ruggieri

Department of Clinical Neurosciences, Guy's, King's, and St Thomas's School of Medicine, London, UK R Ferner

Correspondence to: Dr Upadhyaya

Revised version received 8 June 1999

Accepted for publication

5 August 1999 sheath, composed predominantly of Schwann cells and fibroblasts, but in addition contain axons, perineurial cells, mast cells, and extracellular matrix. Plexiform neurofibromas are usually more extensive as their growth occurs along the length of a nerve and may involve multiple fascicles. Histopathology indicates that plexiform neurofibromas usually contain multiple cell types typical of neurofibromas, but also contain a greatly expanded extracellular matrix. ${ }^{7}$ Although similar to dermal neurofibromas, plexiform neurofibromas do have the potential to become malignant.

Almost all reported NF1 mutations are predicted to lead to neurofibromatosis by the direct inactivation of the gene; this property coupled with its known role in downregulating the ras pathway has led to the hypothesis that NF1 is a tumour suppressor gene. ${ }^{8}$ Knudson's "two hit" hypothesis of tumourigenesis requires the biallelic inactivation of a specific gene for it to be considered as a tumour suppressor. ${ }^{9}$ Studies on a number of tumour suppressor genes have shown that the second (somatic) inactivating mutation often results from the loss of the chromosomal region containing the suppressor gene. The resultant hemizygosity for such a chromosomal region can be monitored by screening the patient's DNA with polymorphic markers from within the deleted region. Thus, a search for evidence of loss of heterozygosity ( $\mathrm{LOH}$ ) within a particular gene region should identify such deletions.

There have been few reports identifying the biallelic inactivation of the NF1 gene in a tumour. An initial study by Coleman et $a l^{10}$ showed LOH in more than $36 \%(8 / 22)$ of the dermal neurofibromas they analysed from five unrelated NF1 patients, while Serra et $a l^{11}$ found $\mathrm{LOH}$ in only $25 \%$ of the 60 neurofibromas they screened. In direct contrast, however, a recent study by Daschner et $a l^{12}$ found little evidence for any $\mathrm{LOH}$ across the entire NF1 gene region. Only $2.6 \%$ of the 38 neurofibromas they examined showed a deletion. ${ }^{12}$

In this study, we have identified LOH in $12 \%$ of 82 neurofibromas screened from 45 patients using a panel of 13 markers. We also report the first case in which both the germline and somatic NF1 mutations have been identified in DNA from a plexiform neurofibroma. A somatic nonsense mutation was detected in exon 16 (R816X) on the normal NF1 allele and the constitutional sequence alteration was subsequently found to be a lesion in the obligate donor splice site GT dinucleotides (IVS $4+1 \mathrm{G} \rightarrow \mathrm{A}$ ) of intron 4 . 


\section{Materials and methods}

PATIENTS

Patients were diagnosed as being affected by NF1 according to the diagnostic criteria formulated by the National Institute of Health Consensus Conference (NIH CC) 1987.

TUMOURS

Our tumour panel includes DNA isolated from 82 NF1 specific tumours (74 dermal neurofibromas, three plexiform neurofibromas, two pilocytic astrocytomas, and three schwannomas) from 45 NF1 patients. The corresponding lymphocyte DNA was also available from these patients. Plexiform neurofibromas were sent from clinics with specialist interest in neurofibromatosis.

DNA EXTRACTION

Tumour samples were transported in tissue culture medium and contaminating tissues, including skin, fat, and hair, was carefully dissected away under the supervision of a pathologist.

DNA was extracted by incubating tumour tissue for 1.5 hours at $65^{\circ} \mathrm{C}$ in $10 \%$ SDS, tissue extraction buffer $(5 \mathrm{mmol} / 1 \mathrm{NaCl}, 1 \mathrm{~mol} / 1$ Tris, $0.5 \mathrm{~mol} / 1 \mathrm{EDTA}, 10 \% \mathrm{SDS}$ ) and proteinase $\mathrm{K}$. Phenol/chloroform extraction was carried out and the DNA precipitated by ethanol and 3 mol/1 sodium acetate. Constitutional DNA was extracted from peripheral blood cells by conventional methods. ${ }^{13}$

PCR

Amplification of the DNA was carried out in a $12.5 \mu \mathrm{l}$ volume containing $10 \mathrm{ng} \mathrm{DNA}, 12$ $\mathrm{pmol} / \mathrm{l}$ of each primer, $1.5 \mathrm{mmol} / 1 \mathrm{MgCl}_{2}, 1.25$ mmol/1 each dNTP, 1 U Taq polymerase, and buffer (Qiagen). Reactions were heated to $94^{\circ} \mathrm{C}$ for five minutes and then subjected to 35 cycles at $94^{\circ} \mathrm{C}$ for 30 seconds, $50-58^{\circ} \mathrm{C}$ for 30 seconds, $72^{\circ} \mathrm{C}$ for 30 seconds, with a final extension at $72^{\circ} \mathrm{C}$ for 10 minutes. The NF1 primers used were as previously published. ${ }^{14}{ }^{15}$

LOH STUDIES

A panel of 13 markers ${ }^{16-27}$ (eight intragenic and five extragenic to NF1) were used to screen the panel of 45 tumour and blood pairs (table 1) to examine $\mathrm{LOH}$ in tumour tissue. ${ }^{28}$
HETERODUPLEX ANALYSIS (HA)

A total of 15-20 ng of amplified DNA (two PCR products were pooled to increase sample throughput) was mixed with $1 \mu l 0.1 \mathrm{~mol} / 1$ EDTA, heated to $94^{\circ} \mathrm{C}$ for three minutes, and slowly cooled to $40^{\circ} \mathrm{C}$ over 40 minutes to allow heteroduplex formation. The reannealed product was loaded onto $24 \mathrm{~cm} \times 33 \mathrm{~cm} \times 0.8 \mathrm{~mm}$ gels and electrophoresed at approximately $5 \mathrm{~W} /$ hour until the marker dye front was at least $15 \mathrm{~cm}$ from the origin. ${ }^{29}$

SINGLE STRANDED CONFORMATION

POLYMORPHISM (SSCP) ANALYSIS

Two $\mu 1$ of PCR product (8-10 ng DNA) was diluted 1:5 with loading buffer (95\% formamide, $10 \mathrm{mmol} / 1 \mathrm{NaOH}, 0.25 \%$ bromophenol blue, $0.25 \%$ xylene cyanol) and heated to $94^{\circ} \mathrm{C}$ for three minutes. The product was loaded immediately onto $0.5 \times \mathrm{MDE}$ (Flowgen) gels and electrophoresed at room temperature for 50-150 Watt hours depending on the product size.

SILVER STAINING

Bands were visualised by silver staining. Gels were soaked in $0.1 \%$ silver nitrate for five minutes, rinsed briefly in distilled water, and then soaked in developing solution $(1.5 \%$ sodium hydroxide, $0.01 \%$ sodium borohydride, and $0.15 \%$ formaldehyde) until bands appeared (five to 15 minutes). The bands were fixed by soaking in $0.75 \%$ sodium carbonate for two to five minutes and then rinsed briefly in water. The gel was transferred onto 3MM Whatmann paper and dried at room temperature. Aberrant bands were identified by their differing migration patterns.

SEQUENCING

Exons were amplified by cycle sequencing for 35 cycles using the Thermo Sequenase cycle sequencing kit from Amersham. Primers were labelled using $\left[\gamma \mathrm{P}^{33}\right] \mathrm{dATP}$ (Amersham) and T4 polynucleotide kinase (Promega). Approximately $3 \mu \mathrm{l}(12-20 \mathrm{ng})$ product was diluted 1:1 with loading buffer and run on polyacrylamide gels for 1.5-3 hours at $75 \mathrm{~W} /$ hour.

\section{Results}

Evidence for $\mathrm{LOH}$ of the NF1 region was investigated in the 45 tumour/blood pairs

Table 1 Results of LOH studies at NF1 and flanking polymorphisms in four patients, screened with eight intragenic and five extragenic markers. Black circles denote undeleted regions, white circles denote LOH, black squares denote uninformative loci, and ND denotes samples that would not PCR for that particular marker

\begin{tabular}{|c|c|c|c|c|c|c|c|c|c|c|c|}
\hline \multirow[b]{2}{*}{ Tumour } & \multicolumn{10}{|c|}{ Marker } & \multirow{2}{*}{$\begin{array}{l}\text { Marker } \\
\text { reference }\end{array}$} \\
\hline & $T 11$ & $T 14$ & $T 15$ & $T 19$ & $T 25$ & T33.1 & T33.2 & $T 68.1$ & T68.2 & $T 68.3$ & \\
\hline UT172 & - & - & • & - & - & - & a & $\circ$ & 0 & 0 & 16 \\
\hline НHН202 & - & - & - & - & • & - & - & ND & ND & ND & 17 \\
\hline NF1- E5 RFLP (exon 5) & $\bullet$ & 0 & o & 0 & o & a & . & . & a & $\square$ & 18 \\
\hline NF1- exon 13 & - & - & घ & a & - & - & - & 0 & 0 & 0 & 19 \\
\hline NF1- EV120 (intron 27b) & $\circ$ & $\bullet$ & o & $\bullet$ & $\bullet$ & o & $\circ$ & o & O & o & 20 \\
\hline NF1- 24.8 (intron 27b) & o & - & 0 & - & - & 0 & 0 & - & घ & ! & 21 \\
\hline NF1- 28.4 (intron 27b) & 0 & - & 0 & - & - & - & ! & - & ! & घ & 21 \\
\hline NF1- 53.0 (intron 38) & 0 & - & 0 & - & • & 0 & 0 & 0 & 0 & 0 & 22 \\
\hline NF1- RsaI RFLP (intron 39) & 0 & - & - & - & • & - & - & 0 & 0 & 0 & 23 \\
\hline NF1- PacI RFLP (intron 41) & 0 & $\bullet$ & - & • & $\bullet$ & • & • & ! & n & - & 24 \\
\hline $3^{\prime} \mathrm{C} 3$ & $\bullet$ & $\bullet$ & o & - & a & a & . & " & 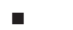 & " & 25 \\
\hline EW207-17cen-q12 & - & - & - & 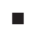 & 口 & 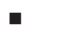 & 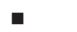 & 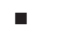 & 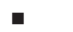 & 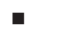 & 26 \\
\hline $\mathrm{D} 17 \mathrm{~S} 250(\mathrm{mfd} 15)$ & 0 & - & 0 & - & - & - & - & - & - & - & 27 \\
\hline
\end{tabular}


A

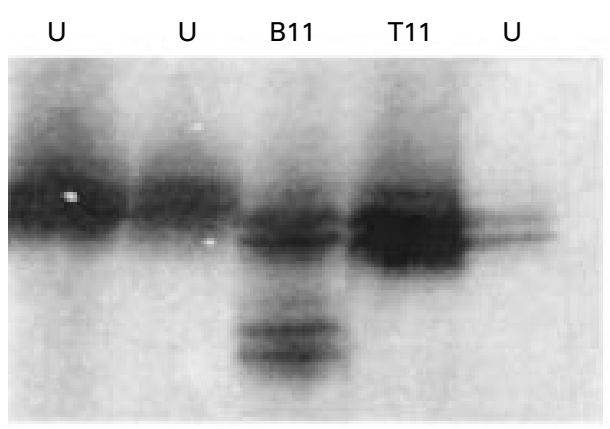

EV120

C

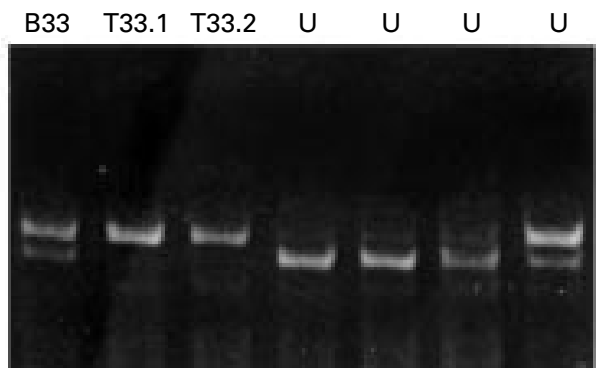

Exon 5
B

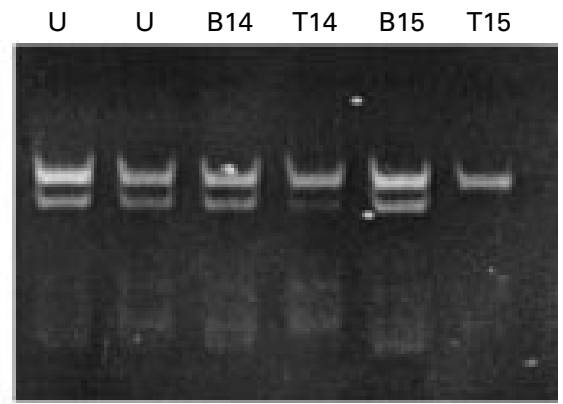

Exon 5

D

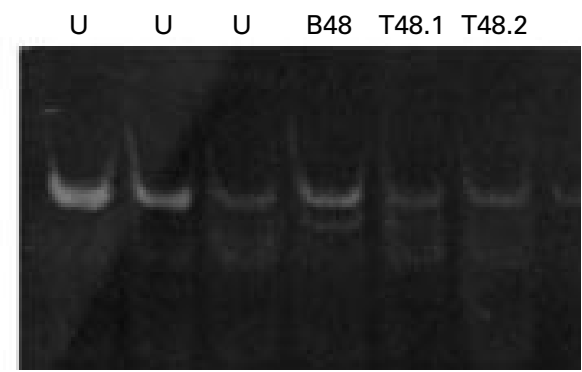

Exon 5

Figure 1 LOH of the NF1 gene region: LOH seen in three patients. (A) Patient T11, LOH at marker EV120 RFLP in intron 27b. (B) Patient T15 and patient T14 both showing LOH at the exon 5 RFLP. (C) Two tumours from patient T33, and (D) two tumours from patient T48, both displaying LOH at the exon 5 RFLP. B=blood DNA, T=tumour DNA, $U=$ other patient samples.

Table 2 Five germline and two somatic mutations identified following a screen of exons 16-40 using SSCP/HA

\begin{tabular}{|c|c|c|c|c|c|}
\hline Patient ID & $\begin{array}{l}\text { Somatic or } \\
\text { germline }\end{array}$ & Mutation & Exon/intron & Restriction site modification & $\begin{array}{l}\text { Amino acid substitution/ } \\
\text { predicted protein changes }\end{array}$ \\
\hline BL7 & G & $\begin{array}{l}\text { IVS } 4+1 \\
\mathrm{G} \rightarrow \mathrm{A}\end{array}$ & Intron 4 & No change & \\
\hline BL22 & G & $\begin{array}{l}\text { IVS } 17-2 \\
\mathrm{G} \rightarrow \mathrm{A}\end{array}$ & Intron 17 & No change & \\
\hline BL62 & G & 4024 del TA & Exon 23-1 & Gain $H p y 178 \mathrm{III}$ site and lose $H_{p y 188 \mathrm{IX}}$ & Premature stop at residue 1344 \\
\hline BL17 & G & 5272 del C & Exon 29 & Gain MseI, DraI & Premature stop at residue 1758 \\
\hline BL23 & G & 7627 del AC & Exon 41 & Gain $D d e I$ & Premature stop at residue 2400 \\
\hline $\mathrm{T} 7$ & $S$ & $\begin{array}{l}\mathrm{R} 816 \mathrm{X} \\
\mathrm{CGA} \rightarrow \mathrm{TGA}\end{array}$ & Exon 16 & No change & Premature stop at residue 815 \\
\hline $\mathrm{T} 52.1$ & S & 7168 delGA & Exon 40 & Lose $H p y 188 \mathrm{IX}, A p o \mathrm{I}$ & Premature stop at residue \\
\hline
\end{tabular}

$\mathrm{S}=$ somatic, $\mathrm{G}=$ germline, $\mathrm{T}=$ tumour, $\mathrm{Bl}=$ blood.

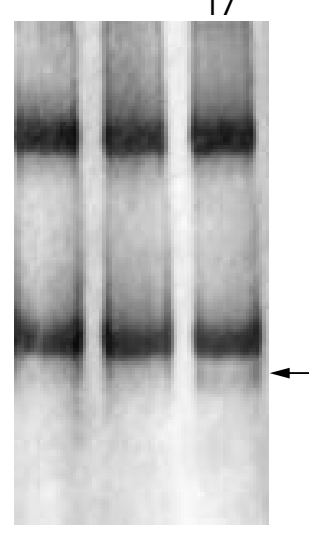

Figure 2 Heteroduplex analysis of exon 16. The arrow points to extra band in patient $T 7$. (table 1). A panel of eight intragenic and five extragenic DNA polymorphic markers was used. $^{28}$ Ten out of $82(12 \%)$ neurofibromas, isolated from seven separate patients, have shown evidence for $\mathrm{LOH}$ (fig 1). The end points of these deletions have not been defined and the constitutional NF1 mutations have still to be identified.

Exons 16-40 (29 exons) of the NF1 gene were targeted for investigation. This conserved region of the gene exhibits extended homology with the yeast IRA1 and IRA2 genes and is still the only domain of the protein to which any function has been ascribed and is involved in the downregulation of the $\mathrm{p}^{21}$ ras oncogene. ${ }^{7}$ The majority of exons (28/29) encompassing this region were screened in this study. Owing to problems associated with the variable quality and quantity of genomic DNA isolated from some tumours, approximately $1-5 \%$ of DNA samples proved to be refractory to mutational analysis. Five novel germline mutations and two somatic sequence alterations were found following the SSCP or HA mutational screen of DNA (table 2).

A band shift was identified by heteroduplex analysis in tumour tissue, but not in lymphocyte DNA, from patient T7 (fig 2). This somatic change, identified in a plexiform neurofibroma from patient $\mathrm{T} 7$, involved a CGA $\rightarrow$ TGA nonsense mutation at nucleotide 2446 of exon 16, resulting in the formation of a premature stop codon at residue 816 (fig 3A). The constitutional mutation in this family was a nucleotide substitution at the obligate donor GT dinucleotides (IVS4+1 G $\rightarrow \mathrm{A}$, intron 4), which was detected in the patient and two affected relatives (fig 3B). RNA was unavailable to confirm splice site abnormalities. A further, novel, somatic change (7168delGA) in 
A

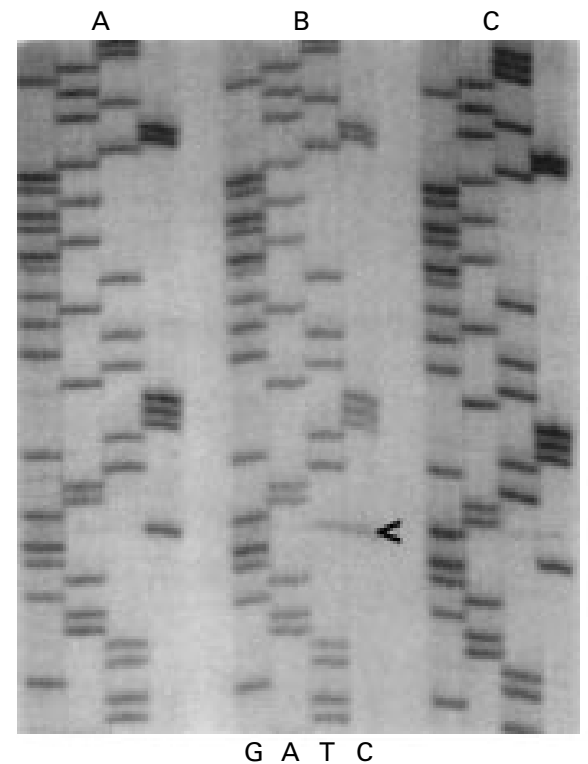

B

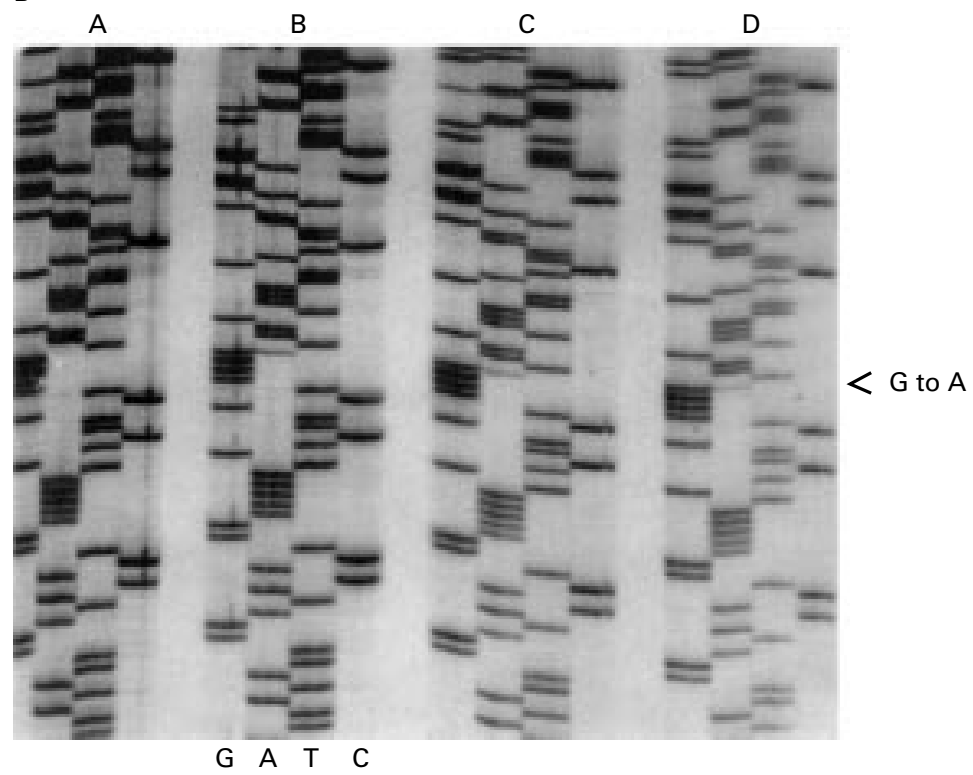

Figure 3 (A) Sequence analysis of the somatic alteration identified in patient T7, a nonsense mutation (R817X) at codon 2446 of exon 16. Lane (A) lymphocyte DNA from the patient, lane (B) DNA from patient's plexiform neurofibroma, lane (C) lymphocyte $D N A$ from patient's mother. (B) Sequence analysis of germline mutation showing a donor splice site change in the obligate $G T$ doublet (IVS4+1 $G \rightarrow A$ ) observed in all affected members of the family of patient T7. Lane $A$ is control DNA, lane B is patient T7 lymphocyte DNA, lane $C$ is patient's tumour DNA, and lane $D$ is lymphocyte DNA from patient's affected mother. tions are frameshift or nonsense mutations that are all predicted to result in the synthesis of a prematurely truncated neurofibromin protein. To date, despite the extensive investigation of the NF1 gene by a number of different mutation screening methods, disease causing lesions have been identified in less than $40 \%$ of patients. ${ }^{31}{ }^{32}$ The spectrum of NF1 germline mutations includes gross deletions, microdeletions, insertions, and base pair substitutions. ${ }^{31}$ The NF1 somatic mutational spectrum is, however, far less well defined, mainly because of the small number of studies carried out and the difficulty in detecting such changes. This study aimed to investigate the possible mutational mechanisms involved in the somatic inactivation of the NF1 gene in various NF1 related tumour tissues.

Searches for evidence of loss of heterozygosity (LOH) of the NF1 gene region have proved successful in identifying potential NF1 deletion mutations in various tumour tissues. ${ }^{10-12} 33$ Three of these studies have provided evidence for at least some degree of LOH of the NF1 gene region in neurofibromas from NF1 patients. Coleman et $a l^{10}$ found that $36 \%(8 / 22)$ of the neurofibromas analysed, derived from five unrelated NF1 patients, showed either partial or complete somatic deletions of one chromosome 17, and that these deletions always involved the NF1 region. ${ }^{10}$ These results were essentially corroborated in a recent study which showed evidence of $\mathrm{LOH}$ in $25 \%$ (15/60) of neurofibromas tested from 17 NF1 patients; again the deletions always included the NF1 gene region. ${ }^{11}$ In contrast to these reports, showing clear evidence for $\mathrm{LOH}$ in more than a third of all neurofibromas analysed, is the recent study from Daschner et $a l^{12}$ who found $\mathrm{LOH}$ in $2.6 \%$ of the 38 neurofibromas they investigated. Our study detected a higher level of $\mathrm{LOH}(12 \%)$ in neurofibromas than Daschner et $a l^{12}$ but it is still significantly less than the previous reports. ${ }^{10}{ }^{11}$ In none of the above studies were the constitutional mutations identified.

In the present study, DNA was isolated from 82 neurofibromas obtained from 45 unrelated $\mathrm{NF} 1$ patients, the largest panel studied to date. Following a screen with a large panel of NF1 intragenic and extragenic polymorphic markers, we identified $\mathrm{LOH}$ in $12 \%(10 / 82)$ of the tumour tissues tested. Indeed, in one case, 12 individual neurofibromas were tested from one NF1 patient and none showed any evidence of genomic deletions with any of the markers screened. To date, the constitutional mutations in six out of seven of the NF1 patients that have shown $\mathrm{LOH}$ in their tumours have still to be determined.

Some of the reasons for the low mutation detection rate could be because the lesions are too small to identify, the alterations being located in the regions still to be screened, or, possibly, the mutation detection techniques used are not sensitive enough. Thorough SSCP/HA analysis of NF1 exons 16-40 for sequence changes has, to date, only detected two somatic mutations and five novel germline mutations (three deletions and two splice site 
changes) (table 2). One of these alterations is located in the GRD region.

Neurofibromas are composed of a mixture of cell types (fibroblasts, mast cells, Schwann cells, perineurial cells) and it is not clear which cell types carry the genetic alterations underlying neurofibromas. Furthermore contamination of tumour DNA by normal cellular DNA will make LOH difficult to detect. Despite every effort to dissect any surrounding normal tissue carefully, it is always difficult to quantify the levels of contaminating normal cells present in any sample of dissected neurofibroma.

Ascertainment of the mutational events underlying the potential "second hit" leading to tumourigenesis in NF1 related tumours proved difficult, with only one study reporting the characterisation of both the germline and somatic changes of the NF1 gene in a dermal neurofibroma from a NF1 patient. ${ }^{34}$ The somatic nonsense mutation $\mathrm{R} 816 \mathrm{X}$ detected in the plexiform neurofibroma from patient $\mathrm{T} 7$ in our study generates a premature protein at residue 816 and the same mutation was previously identified as a disease causing mutation in the lymphocyte DNA from an unrelated NF1 patient. ${ }^{36}$ The constitutional mutation in patient T7 identifies a splice site change IVS4+1 $\mathrm{G} \rightarrow \mathrm{A}$, and this represents a novel mutation of the NF1 gene.

If we assume that our current mutational screening methodologies are sensitive enough to detect the majority of sequence alterations present, then these results would indicate that other mutational mechanisms affecting the NF1 gene are probably involved in neurofibroma formation, and other tumour suppressor genes may play an important role in NF1 tumourigenesis. One inactivating mechanism being increasingly recognised in many tumour suppressor genes is the methylation of gene control regions. Hypermethylation of the gene promoter region has become an important alternative mechanism to specific coding region mutations for the inactivation of a number of tumour suppressor genes during neoplasia. ${ }^{36-39}$ We are currently examining the methylation status of the NF1 promoter region as a potential mechanism for gene silencing. Such hypermethylation of the NF1 gene may account for the low detection rate of somatic mutations within the NF1 coding region in NF1 associated tumours.

The determination of the underlying somatic mutational spectrum is important in helping us to understand the pathogenesis of the NF1 gene better. Before this current study, somatic alterations of the NF1 gene in a plexiform neurofibroma had only been indirectly shown by $\mathrm{LOH}$ studies. We are the first to characterise both the germline and somatic NF1 mutations from within such a tumour. Plexiform neurofibromas are of interest as they appear to be the site of malignant neurofibrosarcoma transformation and hence a better understanding of their developmental mechanism should provide us with further insight into the potential involvement of somatic mutations in NF1 tumourigenesis.
We would like to thank Professor David Cooper and Professor Peter Harper for their encouragement and Dr Nick Thomas for his comments on this manuscript. We are grateful to Dr Susan Huson and all other clinicians who have provided clinical material for this research and the patients and other families for their support. Financial support was provided by the Smiths Charity and the Neurofibromatosis Association.

1 Barker D, Wright E, Nguyen K, et al. Gene for Von Recklinghausen's neurofibromatosis in the pericentric region of chromosome 17. Science 1987; 236:1100-2.

2 Seizinger BR, Rouleau GA, Ozelius Z, et al. Genetic linkage of von Recklinghausen's neurofibromatosis to the nerve of von Recklinghausen's neurofibromatosis to the
growth factor receptor gene. Cell 1987;49:589-94.

3 Viskochil D, Buchberg AM, Xu G, et al. Deletions and translocations interrupt a cloned gene at the neurofibromatranslocations interrupt a cloned gene at
tosis type 1 locus. Cell 1990;62:187-92.

4 Wallace MR, Marchuk DA, Anderson LB, et al. Type 1 neurofibromatosis gene: identification of a large transcript disrupted in three patients. Science 1990;249:182-6.

5 Xu G, O'Connell P, Viskochil D, et al. The neurofibromatosis type 1 gene encodes a protein related to GAP. Cell 1990; 62:599-608.

6 Ferner RE. Medical complications in NF1. In: Upadhyaya M, Cooper DN, eds. Neurofibromatosis type 1: from genotype to phenotype. Oxford: BIOS Publishers, 1998.

7 Korf BR, Huson SM, Needle M, et al. Report on the working group on neurofibroma. USA: The National Neurofibromatosis Foundation, 1997:4-27.

8 Seizinger B. NF1: a prevalent cause of tumourigenesis in human cancers? Nat Genet 1993;3:97-9.

9 Knudson AG. Mutation and cancer: statistical study of neuroblastoma. Proc Natl Acad Sci USA 1971;68:820-3.

10 Colman SD, Williams CA, Wallace MR. Benign neurofibromas in type I neurofibromatosis (NF1) show somatic deletion of the NF1 gene. Nat Genet 1995;11:90-2.

11 Serra E, Puig S, Otero D, et al. Confirmation of the doublehit model for the NF1 gene in benign neurofibromas. Am $\mathcal{F}$ Hum Genet 1997;61:512-19.

12 Daschner K, Assum G, Eisenbath I, et al. Clonal origin of tumour cells in a plexiform neurofibroma with $\mathrm{LOH}$ in intron 38 and in dermal neurofibromas without $\mathrm{LOH}$ of the NF1 gene. Biochem Biophys Res Commun 1997;234:346-50.

13 Sambrook J, Fritsch EF, Maniatis T. Molecular cloning: a laboratory manual. 2nd ed. New York: Cold Spring Harbour Laboratory Press, 1989.

$14 \mathrm{Li}$ Y, O'Connell P, Briedenbach HH, et al. Genomic organisation of the neurofibromatosis 1 gene $(N F 1)$. Genomics 1995;25:9-18.

15 Abernathy CR, Rasmussen SA, Stalker HJ, et al. NF1 mutation analysis using a combined heteroduplex/SSCP approach. Hum Mutat 1997;9:548-54.

16 Shannon KM, O'Connell P, Martin GA, et al. Loss of the normal NF1 allele from the bone marrow of children with type 1 neurofibromatosis and malignant myeloid disorders. N Engl F Med 1997;330:570-601.

17 Hoff M, Nakamura Y, Holm T, et al. Isolation and mapping of a polymorphic DNA sequence pHHH202 on chromosome 17 (D17S33). Nucleic Acids Res 1988;16:781.

18 Hoffmeyer S, Assum G. An Rsa 1 polymorphism in the transcribed region of the neurofibromatosis (NF1) gene. Hum Genet 1994;93:481-2.

19 Regnier V, Danglot G, Nguyen VC, Bernheim A. A Tsp509I variant in exon 13 of the neurofibromatosis type 1 (NF1) gene allows the identification of both alleles at the mRNA level. Hum Genet 1995;96:131-2.

$20 \mathrm{Xu} \mathrm{G,} \mathrm{Nelson} \mathrm{L,} \mathrm{O'Connell} \mathrm{P,} \mathrm{White} \mathrm{R.} \mathrm{An} \mathrm{Alu}$ polymorphism intragenic to the neurofibromatosis type 1 gene (NF1). Nucleic Acids Res 1991;19:3764

21 Lazaro C, Gaona A, Estivill X. Two CA/GT repeat polymorphisms in intron 27 of the neurofibromatosis type 1 (NF1) gene. Hum Genet 1994;93:351-2.

22 Lazaro C, Gaona A, Xu G, Weiss R, Estivill X. A highly informative $\mathrm{CA} / \mathrm{GT}$ repeat polymorphism in intron 38 of the neurofibromatosis type 1 (NF1) gene. Hum Genet 1993;92:429-30

23 Abernathy C, Coleman SD, Wallace MR. A PCR-based test for a polymorphism within the human NF1 gene. Clin Genet 1994;45:313.

24 Purandare SM, Lanyon WG, Connor JM. Characterisation of inherited and sporadic mutations in neurofibromatosis type-1. Hum Mol Genet 1994;3:1109-15.

25 Fain PR, Barker D, Golgar D, et al. Genetic analysis of NF1: identification of close flanking markers on chromosome 17 . Genomics $1988 ; 1: 340-5$.

26 Cowley GS, Murthy AE, Parry DM, et al. Genetic variation in the $3^{\prime}$ untranslated region of the neurofibromatosis 1 gene: application to unequal allelic expression. Som Cell Mol Genet 1998;24:107-19.

27 Weber Jl, Kwitek AE, May PE, Wallace MR, Collins FS, Ledbetter DH. Dinucleotide repeat polymorphisms at the D17S250 and D17S261 loci. Nucleic Acids Res 1990;18: 4640.

28 Upadhyaya M, Ruggieri M, Maynard J, et al. Gross deletions of the neurofibromatosis type 1 (NF1) gene are predominantly of maternal origin and commonly associated with a learning disability, dysmorphic features and developmental delay. Hum Genet 1998;102:591-7.

29 Maynard J, Upadhyaya M. High throughput screening for the detection of unknown mutations: improved productivity detection of unknown mutations: improved productivity
using heteroduplex analysis. Biotechniques 1998;25:648-51.

30 NNFF International NF1 Genetic Analysis Consortium. www.clam.com/nf/nflgene/ 
31 Upadhyaya M, Cooper DN. The mutational spectrum in neurofibromatosis 1 and its underlying mechanisms in neurofibromatosis type 1 . In: Upadhyaya $M$, Cooper DN, eds. Neurofibromatosis type 1: from genotype to phenotype. Oxford: BIOS Publishers, 1998.

32 Cotton RGH. Mutation detection. Oxford: Oxford University Press, 1997.

33 Legius E, Marchuck DA, Collins FS, Glover TW. Somatic deletion of the neurofibromatosis type I gene in a neurofibrosarcoma supports a tumour suppressor gene hypothesis. Nat Genet 1993;3:122-6.

34 Sawada S, Florell S, Purandare SM, Ota M, Stephens K, Viskochil D. Identification of NF1 mutations in both alleles of a dermal neurofibroma. Nat Genet 1996;14:110-12.

35 Maynard J, Krawczak M, Upadhyaya M. Characterisation and significance of nine novel mutations in exon 16 of the neurofibromatosis type 1 (NF1) gene. Hum Genet 1997;99: 674-6.

36 Gonzalez-Zulueta M, Ponder CM, Yang AS, et al. Methylation of the $5^{\prime} \mathrm{CpG}$ island of the $p 16 / C D K N 2$ tumour suppressor gene in normal and transformed human tissues correlates with gene silencing. Cancer Res 1995;55: 4531-5.

37 Herman JG, Latif F, Wong Y, et al. Silencing of the VHL tumour suppressor gene by DNA methylation in renal carcinoma. Proc Natl Acad Sci USA 1994;91:9700-4.

38 Herman G, Merlo A, Mao L, et al. Inactivation of the CDKN2/p16/MTS1 gene is frequently associated with aberrant DNA methylation in all common human cancers. Cancer Res 1995;55:4525-30.

39 Sakai T, Taguchida J, Ohtani J, et al. Allele-specific hypermethylation of the retinoblastoma tumour suppressor gene. Am f Hum Genet 1991;48:880-8. 